\title{
Effects of protein and omega-3 supplementation, provided during regular dialysis sessions, on nutritional and inflammatory indices in hemodialysis patients
}

\author{
This article was published in the following Dove Press journal: \\ Vascular Health and Risk Management \\ 19 March 2012 \\ Number of times this article has been viewed
}

\author{
Zulfitri A Mat Daud' \\ Boniface Tubie ${ }^{2}$ \\ Judy Adams ${ }^{2}$ \\ Tracey Quainton ${ }^{2}$ \\ Robert Osia ${ }^{2}$ \\ Sharon Tubie ${ }^{2}$ \\ Deepinder Kaur ${ }^{1}$ \\ Pramod Khosla' \\ Marina Sheyman ${ }^{2}$ \\ 'Department of Nutrition and Food \\ Science, Wayne State University, \\ ${ }^{2}$ Great Lake Dialysis, LLC, Detroit, \\ MI, USA
}

Purpose: Malnutrition and chronic inflammation in dialysis patients negatively impacts prognosis. However, intervening to correct this problem (through nutritional supplementation) is often hampered by poor compliance due to both medical and socioeconomic barriers. We have therefore performed a pilot study to investigate the technical feasibility of "directly observed treatment" of nutritional supplementation (protein and omega-3 fatty acids), administered during regular dialysis sessions. Secondary end points included observation of nutritional and inflammatory status of hypoalbuminemic patients undergoing hemodialysis.

Methods: Main inclusion criteria were serum albumin $\leq 3.9 \mathrm{~g} / \mathrm{dL}$ ( 3 months prior to the study). Sixty-three eligible patients agreed to participate. Two intervention groups received $30 \mathrm{~mL}$ of a liquid protein supplement plus either $2.4 \mathrm{~g}$ omega-3 (1800 mg eicosapentaenoic acid $+600 \mathrm{mg}$ docosahexaenoic acid) or a placebo, three times per week after their routine dialysis session for 6 months. Serum albumin, plasma lipids, and other indicators of nutritional and inflammatory status were measured.

Results: Directly observed nutritional supplementation resulted in a significant improvement in the low density lipoprotein cholesterol/high density lipoprotein cholesterol ratio in the omega-3 group as compared to the placebo group $(P=0.043)$. For the omega-3 group, serum albumin was also marginally higher after 6 months as compared to baseline $(P=0.07)$. The observed increase in C-reactive protein in the placebo group over 6 months was not apparent in the omega-3 group, although there was no significant difference between groups. Nuclear factor kappa B, malnutrition-inflammation score, normalized protein nitrogen appearance, body mass index, and hemoglobin were unaffected by the intervention.

Conclusion: "Directly observed treatment" with an omega-3 based supplement (as opposed to a pure protein supplement) showed beneficial effects on the lipid profile, and C-reactive protein levels. Further studies using a combination of outpatient and inpatient "directly observed treatment" of omega-3 based supplementation is warranted.

Keywords: protein and omega-3 supplementation, inflammation, nutritional status, hemodialysis

\section{Introduction}

Cardiovascular disease (CVD) represents the major source of morbidity and is a leading cause of death in uremic patients on chronic hemodialysis. ${ }^{1}$ From nontraditional CVD risk factors in dialysis patients, a malnutrition-inflammation complex syndrome (MICS) has been postulated to play a role in the etiology of premature CVD
Department of Nutrition and Food Science, Room 3002 Science Hall, Wayne State University, 5045 Cass Avenue, Detroit, MI 48202, USA

Tel + I 3135770448

Email aa0987@wayne.edu 
in hemodialysis patients. ${ }^{2}$ Thus, there is considerable interest in finding appropriate interventions for the MICS in this population.

Protein energy malnutrition is highly prevalent in dialysis patients which negatively impacts prognosis. Protein energy malnutrition is implicated in a complex syndrome caused by nutritional and non-nutritional factors such as deficient food ingestion secondary to uremia, dietary restriction, chronic inflammatory state, and increased catabolism related to treatment modalities, nutrients loss in dialysate, and metabolic acidosis. ${ }^{3}$ Numerous studies have demonstrated that protein supplementation alone may improve protein metabolism and nutritional parameters and therefore improve clinical outcomes. ${ }^{4-6}$ Meanwhile, causes of inflammation are multifactorial including exposure of blood to dialyzer membranes or tubing, infection on vascular access, reduced antioxidants, and increased oxidative stress..$^{3,7}$ Therefore, in order for a nutritional intervention to be most effective, it should be targeted at improving protein status and have anti-inflammatory properties. ${ }^{8}$

There is a growing scientific interest in the application of omega-3 fatty acids as a means to prevent CVD in dialysis patients. Omega-3 fatty acids have been postulated to reduce pro-inflammatory response, confer antithrombotic properties, improve lipid levels (particularly triglycerides), and improve endothelial function. ${ }^{9-12}$ To date, there is no well-established recommendation on omega- 3 fatty acid supplementation in the dialysis population despite the fact that these patients have lower omega-3 intake ${ }^{13}$ and plasma levels. ${ }^{14}$ Some of the studies published used supraphysiological doses of omega-3 (>3 g/day) which required a high number of capsules and may have been difficult to consume long term. ${ }^{15}$ Moreover, there may be barriers to compliance with this type of nutritional intervention, especially when the study population includes non-Caucasian races, low income groups, and the unemployed. ${ }^{16}$ Some of the clinical studies relied only on subjective methods such as pill counting to measure compliance. ${ }^{17,18}$

Therefore, we performed a pilot study to investigate the technical feasibility of "directly observed treatment" of nutritional supplementation administered during regular dialysis sessions. Secondary outcomes included observations on nutritional and inflammatory status of hypoalbuminemic patients undergoing hemodialysis. We hypothesized that a combination of protein and omega-3 supplementation would be more effective than protein supplementation alone in improving nutritional and inflammatory status.

\section{Methods}

\section{Patients}

Patients who were undergoing routine hemodialysis treatment at the Great Lake Dialysis Clinic in Detroit, MI, were screened $(n=105)$. Selection criteria included serum albumin levels not meeting the outcome goal of the Kidney Disease Outcome Quality Initiative (KDOQI) guidelines ${ }^{19}$ ( $\leq 3.9 \mathrm{~g} /$ $\mathrm{dL}$ ), age greater than 18 years, and ongoing dialysis treatment for at least 3 months prior to the study. Patients who were residents of nursing homes, receiving intradialytic parenteral nutrition or tube feeding, undergoing 8 hours of dialysis treatment, undergoing nocturnal dialysis, serum albumin $>$ $3.9 \mathrm{~g} / \mathrm{dL}$, or who had fish allergies were excluded.

\section{Study design and procedures}

The present study was approved by the Human Ethics Committee of Wayne State University and the Human Investigation Committee of Great Lakes Dialysis. Informed written consent was obtained from all patients. Eligible subjects $(n=63)$ were randomized into two groups; placebo + protein supplement (placebo, $\mathrm{n}=32$ ) and omega-3 + protein supplement (omega-3, $\mathrm{n}=31$ ). Patients, care givers, and investigators were blinded from group assignments. The study lasted 6 months.

\section{Nutritional intervention and compliance}

The nutritional intervention provided comprised two components. Both treatment groups received a blend of $30 \mathrm{~mL}$ liquid protein supplement (Proteinex ${ }^{\circledR}$; Llorens Pharmaceuticals Inc, Miami, FL) in $60 \mathrm{~mL}$ of apple juice providing $100 \mathrm{kcal}, 18 \mathrm{~g}$ protein, and $8 \mathrm{~g}$ carbohydrate (specifically, $30 \mathrm{~mL}$ of Proteinex provides $18 \mathrm{~g}$ of protein hydrolysate [72 kcals], with $1440 \mathrm{mg}$ of L-arginine, $540 \mathrm{mg}$ of L-leucine, $420 \mathrm{mg}$ of L-phenylalanine, $132 \mathrm{mg}$ of L-histidine, $780 \mathrm{mg}$ of L-lysine, $360 \mathrm{mg}$ of L-isoleucine, $132 \mathrm{mg}$ of L-methionine, and $66 \mathrm{mg}$ of L-tryptophan). Additionally, subjects were given four capsules of either omega-3 or placebo, formulated by Twin Rivers Technologies (Quincy, MA). Each of the omega-3 capsules contained $150 \mathrm{mg}$ of docosahexaenoic acid (DHA) and $450 \mathrm{mg}$ of eicosapentaenoic acid (EPA; total DHA $600 \mathrm{mg}$, total EPA $1800 \mathrm{mg}$ ), while the other capsule was a placebo comprised of olive oil. Analysis of omega-3 and placebo capsules is presented in Table 1. Both protein and capsules were given to the patients three times a week after their regular dialysis session for a total duration of 6 months. Compliance was ascertained by administering the supplements during the patients' dialysis session with 
Table I Selected fatty acid composition of omega-3 and placebo capsule

\begin{tabular}{|c|c|c|}
\hline & $\begin{array}{l}\text { Omega-3 } \\
\text { (g//00 g as FA) }\end{array}$ & $\begin{array}{l}\text { Placebo } \\
\text { (g//00 g as FA) }\end{array}$ \\
\hline $\mathrm{Cl} 6: 0$ & 0.96 & 13.86 \\
\hline CI6:I & 0.35 & 1.44 \\
\hline CI7:0 & 0.14 & 0.07 \\
\hline CI7:I & - & 0.11 \\
\hline CI8:0 & 4.66 & 2.73 \\
\hline CI8: In9 & 8.88 & 66.64 \\
\hline CI8:2n6 & 2.00 & 11.42 \\
\hline $\mathrm{Cl} 8: 3 \mathrm{n} 3$ & 0.77 & 0.69 \\
\hline$C 20: 0$ & 0.50 & 0.43 \\
\hline$C 20: \ln 9$ & - & 0.26 \\
\hline$C 20: 5 n 3$ & 35.36 & - \\
\hline$C 21: 5 n 3$ & 1.70 & - \\
\hline$C 22: 5 n 3$ & 4.95 & - \\
\hline$C 22: 6 n 3$ & 24.31 & - \\
\hline SAFA & 7.02 & 17.26 \\
\hline MUFA & $|5.2|$ & 70.63 \\
\hline PUFA & 77.77 & 12.11 \\
\hline Omega-3 & 67.08 & 0.69 \\
\hline
\end{tabular}

Abbreviations: FA, fatty acids; SAFA, saturated fatty acids; MUFA, monounsaturated fatty acids; PUFA, polyunsaturated fatty acids.

close monitoring by nurses. Tolerability and side effects of supplements were recorded by registered nurses and hospitalization rates were also monitored.

\section{Blood sampling and laboratory measures}

The study flow chart is shown in Figure 1. Approximately $20 \mathrm{~mL}$ of fasting blood sample was taken prior to the dialysis session. Plasma samples intended for lipid analysis were isolated from blood by centrifugation at $3000 \mathrm{rpm}$ for 20 minutes at $4^{\circ} \mathrm{C}$ and were kept at $4^{\circ} \mathrm{C}$ to be analyzed on the following day. Blood samples for nuclear factor kappa B (NFKB) were processed immediately to obtain mononuclear cell extract using the Ficoll-Paque method ${ }^{20}$ and the extract was kept at $-80^{\circ} \mathrm{C}$ until further analysis. Serum samples for common renal profiles (serum albumin, blood-urea-nitrogen, creatinine, hemoglobin) were sent to Satellite Laboratory Services (Redwood City, CA) for analysis and were measured using standard automated laboratory techniques.

\section{Lipids analysis}

Total cholesterol, high density lipoprotein (HDL) cholesterol, and triacylglycerol (TAG) in the plasma were determined by enzymatic reaction using kits purchased from Pointe Scientific Inc (Canton, MI). Low density lipoprotein (LDL) cholesterol was calculated using the Friedwald equation (LDL-C $=$ total cholesterol minus HDL-C minus TAG/5).
LDL-C to HDL-C ratio was calculated by dividing LDL-C by HDL-C values.

\section{Inflammatory markers}

Serum C-reactive protein (CRP) was analyzed by an independent laboratory (DMC Laboratory, Detroit, MI) using an immunoturbidimetric method. Activated NFKB was measured from the nuclear extracts using a TransAm chemiluminescent (p65) kit purchased from Active Motif (Carlsbad, CA) using the procedure described by the manufacturer.

\section{Nutritional indicators}

Serum albumin was measured by the bromocresol green method using standard automated laboratory techniques. Normalized protein nitrogen appearance (nPNA) was calculated according to K/DOQI guidelines (2000). ${ }^{19}$ The malnutrition-inflammation score (MIS) questionnaire ${ }^{21}$ was also administered prior to (baseline), during (month 2) and at the end of the study (month 6). MIS is a quantitative scoring system that comprises ten components related to patients' medical history, physical exam, body mass index (BMI), and laboratory parameters, which has been reported to be a useful tool to predict dialysis outcome, malnutrition, and inflammatory status. ${ }^{22-24}$ MIS was performed and calculated by a single person, a registered dietitian, to minimize interobserver variability.

\section{Statistical analysis}

The minimum sample size for each group was $n=31$, which was estimated at a power of $80 \%$ and $\alpha=0.05$ for a twoarm parallel study to detect a $0.2 \mathrm{~g} / \mathrm{dL}$ difference in serum albumin. Results were analyzed using intention to treat. All study participants were maintained in the treatment groups to which they were randomized regardless of post randomization withdrawal and any missing values reported accordingly. Categorical data are reported as number and percentage, while continuous data are reported as mean \pm standard deviation (SD) or as otherwise stated. Independent $t$-test was used to determine differences in the variables of interest between the two groups at baseline. The difference between baseline and month 2 and between baseline and month 6 for each group were tested using a paired $t$-test. Data that were not normally distributed were tested using a nonparametric test. Statistical significance was set at $\alpha=0.05$. All statistical tests were performed using SPSS (v 16.0; IBM, Chicago, IL). As there was no significant difference between baseline and the 2-month values in any of the parameters measured, these are not discussed further (data not shown). 


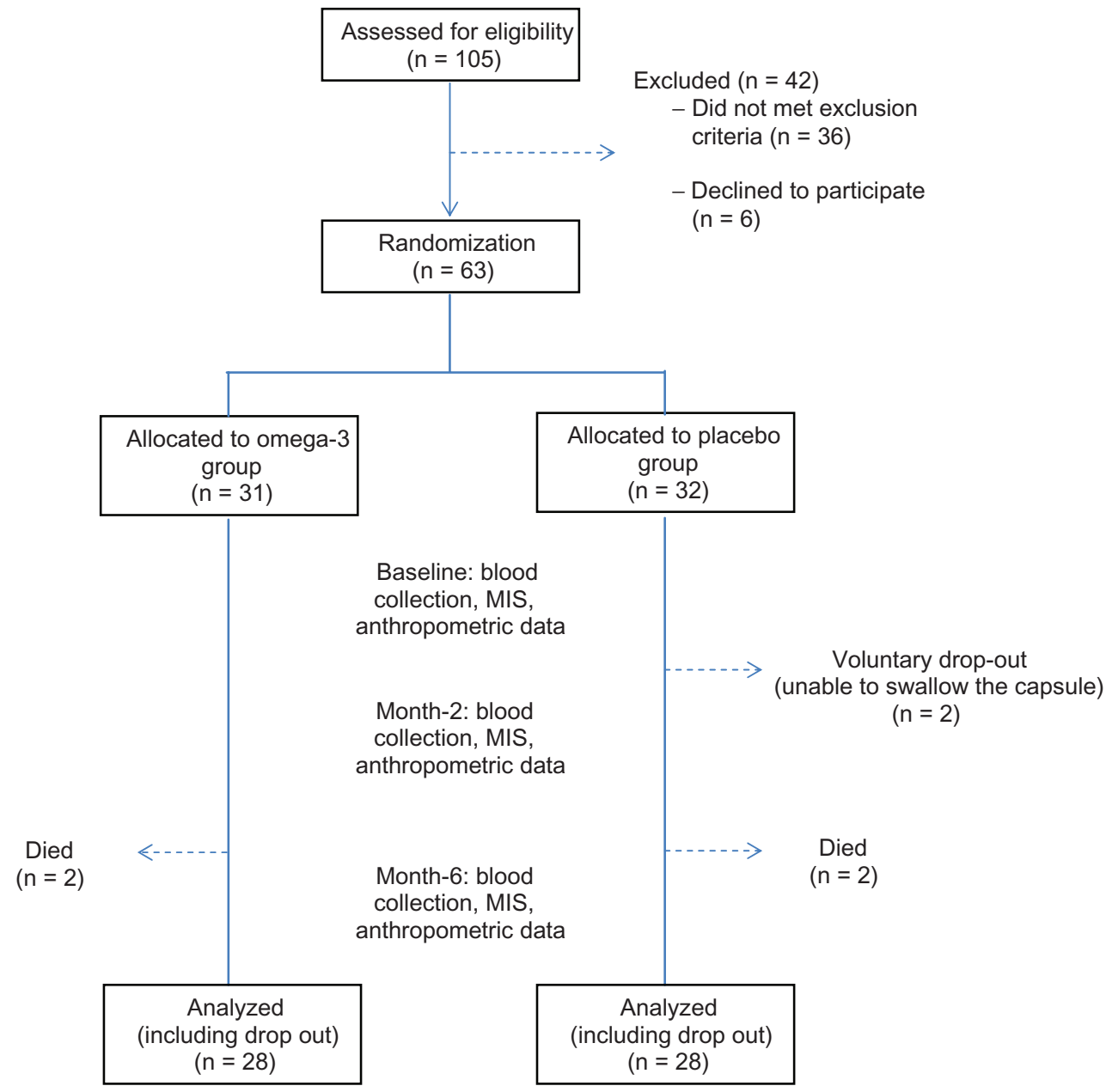

Figure I Study's flow chart.

Notes: All patients at the Great Lake Dialysis clinic $(n=105)$ were screened for eligibility. Sixty-nine patients met the inclusion criteria but six of them declined to participate. The remaining 63 patients were randomized into omega-3 and placebo groups and underwent intervention for 6 months. Seven additional subjects (placebo, $n=4$; omega-3, $n=3$ ) were excluded from data analysis due to death $(n=4,2$ from each group) or hospitalization $(n=3)$. Two patients voluntarily dropped out as they were unable to swallow the capsules but their data were included in the analysis (intent to treat).

Abbreviation: MIS, malnutrition-inflammation score.

\section{Results}

\section{Demographic profiles}

The inclusion criteria were met by 69 patients and 63 agreed to participate. Subjects were randomized based on albumin levels, and with the exception of gender distribution, there were no significant differences in age, duration on dialysis, BMI, and prevalence of existing comorbidity (diabetes mellitus) or indicators of dialysis adequacy (Kt/v) between the two groups (Table 2). The study population was homogenously comprised of African-American ethnicities with no difference in income between groups.

\section{Tolerability, side effects, and compliance}

Over the course of the study, four patients died due to (a) cerebrovascular accident (placebo group, $\mathrm{n}=1$ ), (b) diabetic infection (omega-3 group, $\mathrm{n}=1$ ) and (c) CVD (one patient from each group). There were no other adverse events reported (ie, a life-threatening adverse effect, inpatient hospitalization or prolongation of existing hospitalization, or a persistent or significant disability/incapacity), over the course of the study. No discernible "fishy" smells were reported by any of the patients with regards to capsule assignment. Two patients complained they could not swallow the pills (placebo group) and withdrew from the study (Figure 1). Twenty-one patients (33\%) were able to take $100 \%$ of the supplements provided during the 6 -month study period. Sixty-seven percent of the patients $(n=22$ in the omega-3 group and $\mathrm{n}=21$ in the placebo group) were able to take greater than $80 \%$ of the supplements. The principal reason for lack of compliance was subjects who missed their scheduled dialysis sessions. 
Table 2 Clinical and demographic characteristics of the study population

\begin{tabular}{|c|c|c|c|}
\hline & $\begin{array}{l}\text { Omega-3 } \\
(n=3 I)\end{array}$ & $\begin{array}{l}\text { Placebo } \\
(n=32)\end{array}$ & $P$-value \\
\hline \multicolumn{4}{|l|}{ Demographics } \\
\hline Age (years) & $59 \pm 13$ & $58 \pm 13$ & 0.845 \\
\hline \multicolumn{4}{|l|}{ Ethnicity } \\
\hline African American (n, \%) & $30(97)$ & $32(100)$ & - \\
\hline Caucasian (n, \%) & I (3) & $0(0)$ & - \\
\hline Gender (males, \%) & $20(62.5)$ & $12(38.7)$ & 0.059 \\
\hline Income (\$ per month) & $1015 \pm 576$ & $|148 \pm 76|$ & 0.552 \\
\hline \multicolumn{4}{|l|}{ Clinical } \\
\hline Time on dialysis (years) & $3.6 \pm 2.9$ & $3.3 \pm 3.8$ & 0.784 \\
\hline BMI $\left(\mathrm{kg} / \mathrm{m}^{2}\right)$ & $28.4 \pm 8.3$ & $26.9 \pm 7.8$ & 0.468 \\
\hline Diabetes mellitus (n, \%) & $20(62.5)$ & $20(64.5)$ & 0.868 \\
\hline $\mathrm{Kt} / \mathrm{v}$ & $1.58 \pm 0.29$ & $1.63 \pm 0.32$ & 0.536 \\
\hline Statin usage (n, \%) & II (35.5) & $9(28.1)$ & 0.530 \\
\hline CRP (mg/dL) & $5.8 \pm 9.2$ & $4.9 \pm 5.6$ & 0.134 \\
\hline
\end{tabular}

Notes: Differences in age, time on dialysis, $\mathrm{BMI}, \mathrm{Kt} / \mathrm{v}$ and income were tested using independent $t$-test. Baseline CRP levels are reported in median \pm interquartile range. Differences were tested using Mann-Whitney rank-sum test. Differences in gender, diabetes mellitus, and statin treatment were tested using chi-square. $P<0.05$ is considered significant.

Abbreviations: $\mathrm{BMI}$, body mass index; $\mathrm{Kt} / \mathrm{v}$, index of dialysis adequacy; CRP, C-reactive protein.

\section{Effects on lipid profiles}

One subject was excluded from the analysis due to high TAG levels $(478 \mathrm{mg} / \mathrm{dL})$ as the Friedwald equation for LDL-C estimation is not reliable when TAG levels exceed $400 \mathrm{mg} / \mathrm{dL} .{ }^{25}$ Total cholesterol was significantly reduced over the 6 months intervention in both groups $(P<0.001$; Table 3). At the end of 6 months, the reduction in total cholesterol in the omega-3 group $(-37 \pm 32 \mathrm{mg} / \mathrm{dL})$ was approximately $50 \%$ greater than the reduction seen in the placebo group $(-21 \pm 26 \mathrm{mg} / \mathrm{dL}, P=0.057)$. While HDL-C levels were increased at month-6 compared to baseline in both groups ( $t=-4.077, P=0.000$ and $t=-3.410, P=0.004$, respectively), there was no significant difference between groups $(P=0.531)$. LDL-C was reduced in both groups (omega-3 group: $t=6.083, P=0.000$, placebo group: $t=4.200, P=0.000)$ at month- 6 compared to baseline, however, no significant differences between the two groups were noted at the end of the study $(P=0.092)$. The LDL-C/HDL-C ratios were significantly improved in both groups compared to baseline (omega- 3 group: $t=5.875, P=0.000$, placebo group: $t=4.683, P=0.000)$. After 6 months, the omega- 3 group had a significantly larger reduction in LDL-C/HDL-C ratio compared to the placebo group $(-1.3 \pm 1.1$ versus $-0.7 \pm 0.8$, $P=0.043)$. Compared to baseline, TAG levels did not change significantly in the placebo group $(P=0.561)$, while there was a tendency for a decline in the omega-3 group $(P=0.064)$.

\section{Effects on nutritional parameters}

Serum albumin and other nutritional indices are presented in Table 4. Serum albumin at the end of the study was comparable to the values observed at baseline in both the omega-3 $(t=-1.895, P=0.070)$ and placebo $(t=-0.314$, $P=0.756)$ groups. Comparison between both groups showed no significant difference $(P=0.295)$. Similarly, no changes were observed in MIS score, nPNA, and BMI following the intervention within or between the groups. Additionally, hemoglobin levels were not changed following intervention in both groups (omega-3 group: $t=1.100, P=0.282$, placebo group: $t=-0.731, P=0.471)$.

\section{Effects on inflammatory indicators}

The NFKB levels observed after 6 months in the omega-3 and placebo groups were similar to baseline values (Table 5). Additionally, mean differences (month-6 minus baseline) between omega-3 and placebo groups were not significantly different $(P=0.134)$. With regards to CRP levels, mean values showed a significant elevation in the placebo

Table 3 Means and standard deviations of lipid profiles (TC, HDLC, LDLC, and TAG) at baseline and month-6

\begin{tabular}{|c|c|c|c|c|c|c|c|c|c|}
\hline & \multicolumn{4}{|c|}{ Placebo $(n=26)$} & \multicolumn{4}{|c|}{ Omega-3 $(n=28)$} & \multirow[t]{2}{*}{$P$ overall } \\
\hline & Baseline & Month-6 & Diff & $P$ & Baseline & Month-6 & Diff & $P$ & \\
\hline \multicolumn{10}{|l|}{ Lipid profiles } \\
\hline TC (mg/dL) & $159 \pm 49$ & $138 \pm 42$ & $-21 \pm 26$ & 0.000 & $176 \pm 36$ & $139 \pm 29$ & $-37 \pm 32$ & 0.000 & 0.057 \\
\hline HDLC (mg/dL) & $44 \pm 13$ & $49 \pm 11$ & $+5 \pm 8$ & 0.004 & $41 \pm 14$ & $47 \pm 16$ & $+6 \pm 8$ & 0.000 & 0.531 \\
\hline LDLC (mg/dL) & $94 \pm 42$ & $69 \pm 35$ & $-25 \pm 27$ & 0.000 & $108 \pm 34$ & $71 \pm 29$ & $-39 \pm 33$ & 0.000 & 0.092 \\
\hline TAG (mg/dL) & $104 \pm 69$ & $96 \pm 68$ & $-7 \pm 61$ & 0.561 & $123 \pm 60$ & $102 \pm 53$ & $-20 \pm 55$ & 0.064 & 0.405 \\
\hline LDL-HDL ratio & $2.2 \pm 1.0$ & $1.5 \pm 0.9$ & $-0.7 \pm 0.8$ & 0.000 & $3.0 \pm 1.6$ & $1.7 \pm 1.0$ & $-1.3 \pm I .1$ & 0.000 & 0.043 \\
\hline
\end{tabular}

Notes: All values are presented as mean \pm SD. $P$ values for each group derived from paired $t$-test between baseline versus month- 6 comparison. Overall $P$ values derived using independent $t$-test, tested for mean differences of lipid profiles parameters between omega-3 and placebo groups (bold face). Data excludes values from 7 subjects (placebo, $n=4$; omega-3, $n=3$ ) who died ( $n=4,2$ from each group), or were hospitalized $(n=3)$, during the course of the study. One subject (placebo) was excluded due to extremely high TAG levels $(478 \mathrm{mg} / \mathrm{dL}$ ) as the Friedwald equation is not reliable when TAG levels exceed $400 \mathrm{mg} / \mathrm{dL}$.

Abbreviations: TC, total cholesterol; HDLC, high density lipoprotein cholesterol; LDLC, low density lipoprotein cholesterol; TAG, triacylglycerides; Diff, mean difference of month-6 minus baseline. 
Table 4 Means and standard deviations of nutritional status indicators (Ser alb, Hgb, MIS score, nPNA, and BMI) at baseline and month-6

\begin{tabular}{|c|c|c|c|c|c|c|c|c|c|}
\hline & \multicolumn{4}{|c|}{ Placebo $(n=27)$} & \multicolumn{4}{|c|}{ Omega-3 $(n=28)$} & \multirow[t]{2}{*}{$P$ overall } \\
\hline & Baseline & Month-6 & Diff & $\mathbf{P}$ & Baseline & Month-6 & Diff & $P$ & \\
\hline \multicolumn{10}{|c|}{ Nutritional status } \\
\hline Ser alb (g/dL) & $3.7 \pm 0.2$ & $3.8 \pm 0.4$ & $0.0 \pm 0.3$ & 0.756 & $3.6 \pm 0.3$ & $3.7 \pm 0.3$ & $0.1 \pm 0.3$ & 0.070 & 0.295 \\
\hline $\mathrm{Hgb}(g / L)$ & $11.0 \pm 1.0$ & $11.3 \pm 1.7$ & $0.2 \pm 1.7$ & $0.47 I$ & $10.4 \pm 1.1$ & $10.8 \pm 1.5$ & $0.3 \pm 1.4$ & 0.282 & 0.866 \\
\hline MIS score & $7.6 \pm 3.6$ & $8.1 \pm 4.0$ & $0.6 \pm 4.0$ & 0.215 & $9.0 \pm 3.6$ & $9.1 \pm 3.4$ & $0.4 \pm 2.2$ & 0.408 & 0.730 \\
\hline nPNA & $0.96 \pm 0.38$ & $0.91 \pm 0.22$ & $-0.01 \pm 0.23$ & 0.810 & $0.99 \pm 0.29$ & $0.87 \pm 0.25$ & $-0.07 \pm 0.45$ & $0.47 \mid$ & 0.598 \\
\hline BMI $\left(\mathrm{kg} / \mathrm{m}^{2}\right)$ & $25.4 \pm 5.6$ & $25.1 \pm 6.1$ & $0.3 \pm 1.8$ & 0.327 & $28.1 \pm 7.0$ & $28.1 \pm 7.2$ & $0.1 \pm 1.0$ & 0.699 & 0.500 \\
\hline
\end{tabular}

Notes: All values are presented as mean \pm SD. $P$ values for each group derived from paired $t$-test between baseline versus month-6 comparison. Overall $P$ values derived using independent $t$-test, tested for mean differences of nutritional parameters between omega- 3 and placebo groups (bold face). Data excludes values from 7 subjects (placebo, $n$ $=4$; omega- $3, n=3)$ who died $(n=4,2$ from each group) or were hospitalized $(n=3)$, during the course of the study.

Abbreviations: Ser alb, serum albumin; Hgb, hemoglobin; MIS, malnutrition inflammation score; nPNA, normalized protein equivalence of nitrogen appearance; BMI, body mass index; Diff, mean difference of month-6 minus baseline.

group $(t=-2.158, P=0.040)$ but not the omega-3 group $(t=-0.582, P=0.565)$ over 6 months. However these differences were not apparent when median CRP values were compared. Additionally, there was a significant inverse association between CRP and albumin levels across both groups $(\mathrm{r}=-0.261, P=0.049)$.

\section{Discussion}

Our study tested the potential of a combination of protein and omega-3 supplementation to improve nutritional and inflammatory markers in chronic hemodialysis patients. To increase compliance the supplements were administered during patients' routine dialysis session, three times per week ("directly observed treatment"). Directly observed treatment allowed for two-thirds of the subjects to receive more than $80 \%$ of the stated overall dose over a 6-month period. While compliance was excellent in patients who came in for regular dialysis sessions, the significant comorbidities within this patient population resulted in a large number of missed dialysis treatments (and hence missed supplementation).

We observed that serum albumin, one of the markers of nutritional status, was not improved significantly in either group following the intervention. This finding was in contrast to what has been reported in previous studies. ${ }^{4-6}$ This may be explained by the fact that only a small number of patients were able to take all of the supplements provided to them (no missing days) during the study course $(\mathrm{n}=21,33.3 \%)$. Patients missed days of supplementation mostly due to frequent hospitalization or because they failed to show up for their routine dialysis treatment, ranging from 1-44 days. Therefore, this could potentially upset the effect of omega-3 and protein supplementation per se. Further analysis on a pool of patients who substantially completed the supplementation course (ie, taking $>80 \%$ of the supplements) showed marginal improvement in serum albumin at month-6 compared to baseline ( $3.6 \pm 0.3 \mathrm{~g} / \mathrm{dL}$ versus $3.7 \pm 0.3 \mathrm{~g} / \mathrm{dL}, P=0.079)$ but no improvements were noted in those who took $<80 \%$ of the supplements ( $3.7 \pm 0.2$ vs $3.7 \pm 0.4, P=0.939)$. Interestingly, nPNA, an indicator of protein intake, remained constant in both groups despite protein supplementation. A similar study by Moretti et al $^{26}$ also noted a similar trend, in which there were no changes in nPCR despite improvement in serum albumin in the protein group for the second 6 months.

Reduced protein intake and an increase in inflammatory response are two important factors that lead to a decrease in serum albumin. ${ }^{27}$ However, Kaysen et $\mathrm{a}^{28}$ had noted that low serum albumin in dialysis patients may be attributed to systemic inflammation rather than nutritional inadequacy

Table 5 Means and standard deviations of inflammatory indicators (NFKB, CRP) at baseline and month-6

\begin{tabular}{|c|c|c|c|c|c|c|c|}
\hline & \multicolumn{3}{|c|}{ Placebo $(n=27)$} & \multicolumn{3}{|c|}{ Omega-3 $(n=28)$} & \multirow[t]{2}{*}{$P$ overall } \\
\hline & Baseline & Month-6 & $\boldsymbol{P}$ & Baseline & Month-6 & $P$ & \\
\hline $\mathrm{NF \kappa B}(\mu \mathrm{g} / \mathrm{mL})$ & $2.48 \pm 1.03$ & $2.54 \pm 1.14$ & 0.703 & $2.52 \pm 1.19$ & $2.15 \pm 0.4$ & 0.129 & 0.134 \\
\hline CRP (mg/dL)* & $6.6 \pm 8.3$ & $11.0 \pm 13.9$ & 0.040 & $13.1 \pm 17.5$ & $14.6 \pm 19.7$ & 0.565 & 0.259 \\
\hline CRP $(\mathrm{mg} / \mathrm{dL})^{* *}$ & $4.9 \pm 5.6$ & $4.6 \pm 12.0$ & 0.034 & $5.8 \pm 9.2$ & $6.1 \pm 14.0$ & 0.412 & 0.326 \\
\hline
\end{tabular}

Notes: NFKB value is presented as mean \pm SD. CRP value is presented as *mean \pm SD and **median \pm IQR. $P$ values for each group derived from either paired $t$-test (NFKB )/Wilcoxon rank sum test (CRP) between baseline versus month-6 comparison. Overall $P$ values derived using either independent $t$-test/Mann-Whitney rank sum test, tested for mean differences of inflammatory parameters between omega-3 and placebo groups (bold face). Data excludes values from 7 subjects (placebo, $n=4$; omega-3, $n=3$ ) who died ( $n=4,2$ from each group) or were hospitalized $(n=3)$, during the course of the study.

Abbreviations: NFאB, Nuclear factor kappa-light-chain enhancer of activated B cells; CRP, C-reactive protein. 
as a causative factor per se. In relation to this, we also observed a significant inverse correlation between serum albumin and CRP which may indicate the influence of an inflammatory process on serum albumin levels. Friedman and Fadem ${ }^{29}$ suggested that serum albumin should be taken as a marker of illnesses rather than nutrition. This is due to the fact that serum albumin has a strong ability to predict mortality but rather limited prediction for nutritional status due to significant influence of non-nutrition causes (such as inflammation).

Many of the omega-3 fatty acid supplementation studies in dialysis patients have described various potential outcomes such as attenuating dyslipidemia, inflammation, and providing a cardioprotective effect. Moreover, there is substantial evidence for reducing TAG levels ${ }^{30-32}$ even at a dosage as low as $1.5 \mathrm{~g}$ /day. ${ }^{33}$ As for plasma TAG, we saw a tendency for a reduction in TAG levels in both groups although in the omega-3 group statistical significance was marginal $(P=0.064)$. The large variation in the difference in TAG changes observed in the placebo group $(-7 \pm 61 \mathrm{mg} / \mathrm{dL}, P=0.56$, Table 3$)$ could be attributed to one subject with very high triglyceride concentrations. Upon removal of this subject the difference in TAG levels between the 6-month and baseline value was $1 \pm 44 \mathrm{mg} / \mathrm{dL}$, $P=0.89$. Thus collectively these data suggest no change in TAG levels over 6 months in the placebo group, while there was a tendency for a reduction in TAG levels in the omega-3 group $(-20 \pm 44 \mathrm{mg} / \mathrm{dL}, P=0.064)$. Previous studies $^{18,34}$ which administered a higher amount of omega-3 per week, with varying percentages of EPA/DHA but with a shorter duration (4-8 weeks), also reported no changes in TAG levels. However, Bouzidi et al reported that a supplementation of $2.1 \mathrm{~g}$ omega-3 daily for 3 months among chronic kidney disease patients reduced TAG levels by $48 \% .{ }^{35}$ However, it is important to note that the baseline TAG levels in their study were much higher than the current study $(275 \pm 58 \mathrm{mg} / \mathrm{dL}$ versus $123 \pm 60 \mathrm{mg} / \mathrm{dL}$ in the omega-3 group). We postulate that, the baseline TAG levels (omega-3 group: $123 \pm 60 \mathrm{mg} / \mathrm{dL}$; placebo group: $104 \pm 69 \mathrm{mg} / \mathrm{dL}$ ) were within the normal levels and thus may not have been sufficiently elevated to achieve a significant reduction. Skulas-Ray et al reported that the extent of TAG lowering with omega-3 is a function of baseline TAG levels. ${ }^{36}$ Omega-3 supplementation resulted in better improvement in LDL-C/HDL-C ratios as compared to placebo which appeared to be due to a greater improvement in non-HDL-C. As for inflammatory markers, our results for CRP were inconclusive. While mean values in the placebo group increased over the 6-month period, this was not the case in the omega-3 group, in which CRP levels stayed the same. Thus omega-3, if not effective in attenuating inflammation, may be beneficial in preventing further increases in inflammatory status. However when the data were evaluated using median CRP values, these differences were no longer apparent suggesting the need for a larger sample size to definitively resolve this issue. Only a small number of studies have investigated the effects of omega-3 on inflammatory markers in hemodialysis patients. It is important to note that most of these studies are not comparable due to differences in study design, supplement dosage, EPA/DHA ratios and study duration. Saifullah et al showed that a supplementation of $1.3 \mathrm{~g}$ of oral EPA and DHA daily over a period of 3 months could modestly reduce CRP levels. ${ }^{37}$ However, a recent study using a larger dosage ( $2.08 \mathrm{~g}$ /day) but a shorter duration (10 weeks) showed no effects on serum systemic inflammatory markers (CRP, interleukin-6, tumor necrosis factor- $\alpha$ ) and oxidative stress (malondialdehyde, total antioxidant capacity).$^{38}$ In a prospective cohort study by Noori et al, the authors showed that a lower omega- 6 to omega-3 ratio $(\sim 6)$ was associated with decreased inflammation and overall mortality in hemodialysis patients which indicates the importance of $n-6 / 3$ polyunsaturated fatty acid ratios in the diet. ${ }^{13}$ However, our study was not designed to investigate the effects of this ratio per se.

$\mathrm{NF} \kappa \mathrm{B}$, a key player in pathogenesis of inflammation, is stimulated by pro-inflammatory agents such as cytokines and CRP. Studies have shown that NFKB activation and subsequent activation of mononuclear cells triggers a process that causes myocardial inflammatory damage in hemodialysis patients. ${ }^{39,40}$ Interestingly, our data for translocation of activated NFKB to the nucleus showed no significant changes following the intervention within and between both groups even though we saw an increase in CRP levels in the placebo group. The latter may have been due to the fact that the baseline CRP values in the placebo group were lower than those assigned to the omega-3 group.

\section{Study limitations}

We were restricted in our patient population to one dialysis clinic for this pilot study. While the lipid data suggested benefits of omega-3, the data for inflammatory markers was less clear cut. One plausible explanation for variation in inflammatory markers in the current study may be related to insufficient dosage/frequency of omega-3 supplementation as well as compliance (due to frequent hospitalization resulting in subjects missing dialysis sessions and 
therefore supplementation). There are several similar studies which also failed to report significant changes in inflammatory markers. ${ }^{18,41-43}$ Studies which demonstrated a significant effect of omega-3 supplementation on inflammation indices are those with a higher dosage and more frequent administration of the supplement (9.1 to $21 \mathrm{~g} /$ week versus $7.2 \mathrm{~g} /$ week $\mathrm{DHA}+\mathrm{EPA}$ in the current study) as well as reported higher patient compliance. ${ }^{17,44-46}$ Another factor that could potentially explain the contradictory finding in our study with those studies is baseline levels of inflammatory markers. Omega-3 supplementation appears to be more effective in studies reporting higher baseline CRP $(>13.8 \mathrm{mg} / \mathrm{dL})$ than those that did not. ${ }^{17,38,44}$

Notwithstanding some of the limitations discussed above, ours is one of the few studies to report on the use of "directly observed treatment" of oral nutritional supplementation with protein and omega-3 in a cohort of hemodialysis patients. Our results suggest that "directly observed treatment" is technically feasible in hemodialysis patients and does not disrupt the normal dialysis schedule. The relatively large number of missed dialysis sessions due to hospitalizations, however, suggests that "directly observed treatment" should be used in the setting of both outpatient and inpatient dialysis sessions in order to optimize compliance. In addition, while emphasizing the huge progressive inflammatory burden in hemodialysis patients over time; this pilot study suggests that "directly observed treatment" with a combination of omega-3 and proteinbased supplement (as opposed to a pure protein supplement) could have some beneficial effects on lipid profile and CRP progression. Further studies using a combination of outpatient and inpatient "directly observed treatment" of fish oil based nutritional supplementation are warranted.

\section{Acknowledgments}

The authors express sincere gratitude to all participants and Great Lake Dialysis Clinic staff for their help and cooperation. The authors are also especially thankful to Janice Jackson, Mariam Beydoun, and Bryan Strouse from Wayne State University for the technical assistance. We are extremely grateful to Dr Prabir Roy-Chaudhury from the Division of Nephrology, University of Cincinnatti, for his critical and helpful comments on the manuscript.

\section{Disclosures}

Omega-3 and placebo capsules were formulated and donated by Twin Rivers Technologies Inc (Cincinnati, OH). The protein supplements were from Llorens Pharmaceuticals Inc
(Miami, FL) including donation for 1 month. The authors declare no conflict of interest in this work.

\section{References}

1. Giray B, Kan E, Bali M, Hincal F, Basaran N. The effect of vitamin $\mathrm{E}$ supplementation on antioxidant enzyme activities and lipid peroxidation levels in hemodialysis patients. Clin Chim Acta. 2003;338(1-2):91-98.

2. Stenvinkel P, Heimburger O, Paultre F, et al. Strong association between malnutrition, inflammation, and atherosclerosis in chronic renal failure. Kidney Int. 1999;55(5):1899-1911.

3. Kalantar-Zadeh K, Ikizler TA, Block G, Avram MM, Kopple JD. Malnutrition-inflammation complex syndrome in dialysis patients: causes and consequences. Am J Kidney Dis. 2003;42(5):864-881.

4. Stratton RJ, Bircher G, Fouque D, et al. Multinutrient oral supplements and tube feeding in maintenance dialysis: a systematic review and meta-analysis. Am J Kidney Dis. 2005;46(3):387-405.

5. Cano N. Nutritional supplementation in adult patients on hemodialysis. J Ren Nutr. 2007;17(1):103-105.

6. Meade A. Protein supplementation with sports protein bars in renal patients. J Ren Nutr. 2007;17(3):214-217.

7. Razeghi E, Omati H, Maziar S, Khashayar P, Mahdavi-Mazdeh M. Chronic inflammation increases risk in hemodialysis patients. Saudi $J$ Kidney Dis Transpl. 2008;19(5):785-789.

8. Kalantar-Zadeh K, Braglia A, Chow J, et al. An anti-inflammatory and antioxidant nutritional supplement for hypoalbuminemic hemodialysis patients: a pilot/feasibility study. J Ren Nutr. 2005;15(3):318-331.

9. Harris WS, Park Y, Isley WL. Cardiovascular disease and long-chain omega-3 fatty acids. Curr Opin Lipidol. 2003;14(1):9-14.

10. Hu FB, Bronner L, Willett WC, et al. Fish and omega-3 fatty acid intake and risk of coronary heart disease in women. JAMA. 2002;287(14):1815-1821.

11. Egert $\mathrm{S}$, Stehle P. Impact of $\mathrm{n}-3$ fatty acids on endothelial function: results from human interventions studies. Curr Opin Clin Nutr Metab Care. 2011;14(2):121-131.

12. Olza J, Mesa MD, Aguilera CM, et al. Influence of an eicosapentaenoic and docosahexaenoic acid-enriched enteral nutrition formula on plasma fatty acid composition and biomarkers of insulin resistance in the elderly. Clin Nutr. 2010;29(1):31-37.

13. Noori N, Dukkipati R, Kovesdy CP, et al. Dietary omega-3 fatty acid, ratio of omega- 6 to omega-3 Intake, inflammation, and survival in longterm hemodialysis patients. Am J Kidney Dis. 2011;58(2):248-256.

14. Madsen T, Christensen JH, Svensson M, Witt PM, Toft E, Schmidt EB. Marine n-3 polyunsaturated fatty acids in patients with end-stage renal failure and in subjects without kidney disease: a comparative study. J Ren Nutr. 2011;21(2):169-175.

15. Friedman A, Moe S. Review of the effects of omega-3 supplementation in dialysis patients. Clin J Am Soc Nephrol. 2006;1(2):182-192.

16. Griffith S. A review of the factors associated with patient compliance and the taking of prescribed medicines. Br J Gen Pract. 1990;40(332):114-116.

17. Bowden RG, Wilson RL, Deike E, Gentile M. Fish oil supplementation lowers $\mathrm{C}$-reactive protein levels independent of triglyceride reduction in patients with end-stage renal disease. Nutr Clin Pract. 2009;24(4):508-512.

18. Poulia KA, Panagiotakos DB, Tourlede E, et al. Omega-3 fatty acids supplementation does not affect serum lipids in chronic hemodialysis patients. J Ren Nutr. 2011;21(6):479-484.

19. K/DOQI. Clinical practice guidelines for nutrition in chronic renal failure. K/DOQI, National Kidney Foundation. Am J Kidney Dis. 2000;35(6 Suppl 2):S1-S140.

20. Ruitenberg JJ, Mulder CB, Maino VC, Landay AL, Ghanekar SA. VACUTAINER CPT and Ficoll density gradient separation perform equivalently in maintaining the quality and function of PBMC from HIV seropositive blood samples. BMC Immunol. 2006;7:11. 
21. Kalantar-Zadeh K, Kopple JD, Block G, Humphreys MH. A malnutrition-inflammation score is correlated with morbidity and mortality in maintenance hemodialysis patients. Am J Kidney Dis. 2001;38(6):1251-1263.

22. Pisetkul C, Chanchairujira K, Chotipanvittayakul N, Ong-Ajyooth L, Chanchairujira T. Malnutrition-inflammation score associated with atherosclerosis, inflammation and short-term outcome in hemodialysis patients. J Med Assoc Thai. 2010;93 Suppl 1:S147-S156.

23. Ho LC, Wang HH, Chiang CK, Hung KY, Wu KD. Malnutritioninflammation score independently determined cardiovascular and infection risk in peritoneal dialysis patients. Blood Purif. 2010;30(1): 16-24.

24. Rambod M, Bross R, Zitterkoph J, et al. Association of MalnutritionInflammation Score with quality of life and mortality in hemodialysis patients: a 5-year prospective cohort study. Am J Kidney Dis. 2009;53(2):298-309.

25. Friedewald WT, Levy RI, Fredrickson DS. Estimation of the concentration of low-density lipoprotein cholesterol in plasma, without use of the preparative ultracentrifuge. Clin Chem. 1972;18(6): 499-502.

26. Moretti HD, Johnson AM, Keeling-Hathaway TJ. Effects of protein supplementation in chronic hemodialysis and peritoneal dialysis patients. J Ren Nutr. 2009;19(4):298-303.

27. Moshage HJ, Janssen JA, Franssen JH, Hafkenscheid JC, Yap SH. Study of the molecular mechanism of decreased liver synthesis of albumin in inflammation. J Clin Invest. 1987;79(6):1635-1641.

28. Kaysen GA, Dubin JA, Muller HG, Rosales L, Levin NW, Mitch WE. Inflammation and reduced albumin synthesis associated with stable decline in serum albumin in hemodialysis patients. Kidney Int. 2004 65(4):1408-1415.

29. Friedman AN, Fadem SZ. Reassessment of albumin as a nutritional marker in kidney disease. J Am Soc Nephrol. 2010;21(2):223-230.

30. Ando M, Sanaka T, Nihei H. Eicosapentanoic acid reduces plasma levels of remnant lipoproteins and prevents in vivo peroxidation of LDL in dialysis patients. J Am Soc Nephrol. 1999;10(10):2177-2184.

31. Vega GL, Chandalia M, Szczepaniak LS, Grundy SM. Effects of N-3 fatty acids on hepatic triglyceride content in humans. J Investig Med. 2008;56(5):780-785.

32. Hauenschild A, Bretzel RG, Schnell-Kretschmer H, Kloer HU, Hardt PD, Ewald N. Successful treatment of severe hypertriglyceridemia with a formula diet rich in omega-3 fatty acids and medium-chain triglycerides. Ann Nutr Metab. 2010;56(3):170-175.

33. Khajehdehi P. Lipid-lowering effect of polyunsaturated fatty acids in hemodialysis patients. J Ren Nutr. 2000;10(4):191-195.

34. Perunicic-Pekovic GB, Rasic ZR, Pljesa SI, et al. Effect of n-3 fatty acids on nutritional status and inflammatory markers in haemodialysis patients. Nephrology (Carlton). 2007;12(4):331-336.
35. Bouzidi N, Mekki K, Boukaddoum A, Dida N, Kaddous A, Bouchenak M. Effects of omega-3 polyunsaturated fatty-acid supplementation on redox status in chronic renal failure patients with dyslipidemia. J Ren Nutr. 2010;20(5):321-328.

36. Skulas-Ray AC, West SG, Davidson MH, Kris-Etherton PM. Omega-3 fatty acid concentrates in the treatment of moderate hypertriglyceridemia. Expert Opin Pharmacother. 2008;9(7):1237-1248.

37. Saifullah A, Watkins BA, Saha C, Li Y, Moe SM, Friedman AN. Oral fish oil supplementation raises blood omega-3 levels and lowers C-reactive protein in haemodialysis patients - a pilot study. Nephrol Dial Transplant. 2007;22(12):3561-3567.

38. Kooshki A, Taleban FA, Tabibi H, Hedayati M. Effects of marine omega-3 fatty acids on serum systemic and vascular inflammation markers and oxidative stress in hemodialysis patients. Ann Nutr Metab. 2011;58(3):197-202.

39. Raj DS, Boivin MA, Dominic EA, et al. Haemodialysis induces mitochondrial dysfunction and apoptosis. Eur J Clin Invest. 2007;37(12):971-977.

40. Shah VO, Ferguson J, Hunsaker LA, Deck LM, Vander Jagt DL. Cardiac glycosides inhibit LPS-induced activation of pro-inflammatory cytokines in whole blood through and NF-kB-dependent mechanism. Int J Appl Res Nat Prod. 2011;4:11.

41. Szklarek-Kubicka M, Fijalkowska-Morawska J, Zaremba-Drobnik D, Ucinski A, Czekalski S, Nowicki M. Effect of intradialytic intravenous administration of omega-3 fatty acids on nutritional status and inflammatory response in hemodialysis patients: a pilot study. J Ren Nutr. 2009;19(6):487-493.

42. Vernaglione L, Cristofano C, Chimienti S. Omega-3 polyunsaturated fatty acids and proxies of cardiovascular disease in hemodialysis: a prospective cohort study. J Nephrol. 2008;21(1):99-105.

43. Fiedler R, Mall M, Wand C, Osten B. Short-term administration of omega-3 fatty acids in hemodialysis patients with balanced lipid metabolism. J Ren Nutr. 2005;15(2):253-256.

44. Saifullah A, Watkins BA, Saha C, Li Y, Moe SM, Friedman AN. Oral fish oil supplementation raises blood omega-3 levels and lowers C-reactive protein in haemodialysis patients - a pilot study. Nephrol Dial Transplant. 2007;22(12):3561-3567.

45. Rasic-Milutinovic Z, Perunicic G, Pljesa S, et al. Effects of N-3 PUFAs supplementation on insulin resistance and inflammatory biomarkers in hemodialysis patients. Ren Fail. 2007;29(3):321-329.

46. Ewers B, Riserus U, Marckmann P. Effects of unsaturated fat dietary supplements on blood lipids, and on markers of malnutrition and inflammation in hemodialysis patients. J Ren Nutr. 2009;19(5):401-411.
Vascular Health and Risk Management

\section{Publish your work in this journal}

Vascular Health and Risk Management is an international, peerreviewed journal of therapeutics and risk management, focusing on concise rapid reporting of clinical studies on the processes involved in the maintenance of vascular health; the monitoring, prevention and treatment of vascular disease and its sequelae; and the involvement of

\section{Dovepress}

metabolic disorders, particularly diabetes. This journal is indexed on PubMed Central and MedLine. The manuscript management system is completely online and includes a very quick and fair peer-review system, which is all easy to use. Visit http://www.dovepress.com/ testimonials.php to read real quotes from published authors. 